\title{
Vogesella mureinivorans sp. nov., a peptidoglycan- degrading bacterium from lake water
}

Correspondence

Niels O. G. Jørgensen nogj@life.ku.dk

\author{
Niels O. G. Jørgensen, ${ }^{1}$ Kristian K. Brandt, ${ }^{1}$ Ole Nybroe ${ }^{1}$ \\ and Michael Hansen ${ }^{2}$
${ }^{1}$ Department of Agriculture and Ecology, University of Copenhagen, Thorvaldsensvej 40, DK-1871 Frederiksberg, Denmark
${ }^{2}$ Department of Plant Biology and Biotechnology, University of Copenhagen, Thorvaldsensvej 40, DK-1871 Frederiksberg, Denmark

\begin{abstract}
A novel, non-pigmented, rod-shaped, Gram-negative strain was isolated from mesotrophic lake water in Zealand, Denmark. Phylogenetic analysis of the 16S rRNA gene sequence of the bacterium, designated strain $389^{\top}$, indicated that the strain belonged to the genus Vogesella and formed a monophyletic group with Vogesella perlucida DS-28 ${ }^{\top}$ (99.1\% nucleotide similarity); it was less related to Vogesella indigofera ATCC $19706^{\top}$ (96.9\% similarity) and Vogesella lacus LMG $24504^{\top}$ ( $96.8 \%$ similarity). Hybridization of DNA from strain $389^{\top}$ and $V$. perlucida demonstrated a reassociation of $50.6 \pm 9.6 \%$. The DNA G $+C$ content of strain $389^{\top}$ was $61.2 \mathrm{~mol} \%$. The fatty acid profile of the strain differed from those of the other strains representing the genus Vogesella by a high content of $\mathrm{C}_{16: 1} \omega 7 \mathrm{c}$ and/or iso- $\mathrm{C}_{15: 0} 2-\mathrm{OH}(71.6 \%)$ and a lower content of $\mathrm{C}_{16: 0}$. Strain $389^{\top}$ was capable of degrading peptidoglycan and had chitinase and lysozyme activities, possibly associated with the degradation of peptidoglycan, and had capacity for degradation of several other polymer compounds. Based on phenotypic and genotypic characteristics, strain $389^{\top}$ represents a novel species, for which we propose the name Vogesella

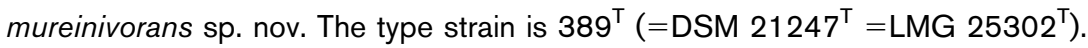

The biomass of prokaryotes on Earth is estimated to equal the entire plant biomass (Whitman et al., 1998). This implies that there is also a considerable global production of peptidoglycan (PG), although some prokaryotes do not contain PG, e.g. Archaea. Specific mechanisms involved in degradation of extracellular PG remain to be characterized, but studies of aquatic bacteria indicate that natural microbial populations exist that can degrade free PG, although at lower rates than other macromolecules, such as proteins (Nagata et al., 2003). In this study, a PGdegrading bacterium belonging to the genus Vogesella was isolated from lake water. The genus Vogesella belongs to the class Betaproteobacteria and includes three recognized heterotrophic species that were all isolated from freshwater sites (sediment or water). The earliest described species of the genus, Vogesella indigofera ATCC $19706^{\mathrm{T}}$, produces distinct blue-pigmented colonies while the other two strains, Vogesella perlucida LMG $24214^{\mathrm{T}}$ and Vogesella lacus LMG $24504^{\mathrm{T}}$ are non-pigmented (Chou et al., 2008,

\section{Abbreviation: $P G$, peptidoglycan.}

The GenBank/EMBL/DDBJ accession number for the 16S rRNA gene sequence of strain $389^{\top}$ is GQ246809.

An illustration of cultures of strain $389^{\top}$ grown with and without $P G$ are available with the online version of this paper.
2009; Grimes et al., 1997). Strain $389^{\mathrm{T}}$ was isolated from freshwater in Denmark by initial cultivation on agar medium enriched with purified PG. Our studies confirmed the capacity to degrade PG and several other polymeric substances. This contrasts the present understanding that members of the genus Vogesella are mainly capable of degrading low-molecular-mass organic compounds.

Lake water was collected from the mesotrophic Lake Sjælsø, northern Zealand, Denmark, and filtered through $0.8 \mu \mathrm{m}$ pore-size filters. The filtered water was enriched with PG from Bacillus sp. strain A6 (Frette et al., 2004) to a final concentration of $2 \mathrm{mg} \mathrm{l}^{-1}$. PG was purified according to a procedure indicated below. After incubation for 7 days on a shaking table at $20{ }^{\circ} \mathrm{C}$, bacteria from the water were cultivated on $1 / 10$ strength Luria-Bertani (LB) agar (Eisenstadt et al., 1994). Isolates from the plates were transferred to $1 / 10$ strength LB agar enriched with PG (or with cell-wall material that had been denatured by heat) of strain A6. Isolates that produced clearing zones on the PGenriched agar medium were picked for further analysis. Strain $389^{\mathrm{T}}$ was found to form distinct, turbid clearing zones, and was selected for additional studies. For subsequent analysis, this strain was cultured in LB broth or tryptic soy broth (TSB; Difco, product no. 0370-17-1) in shake flasks incubated overnight at $22^{\circ} \mathrm{C}$. 
General growth physiology was characterized for strain $389^{\mathrm{T}}$ and $V$. indigofera DSM $3303^{\mathrm{T}}$ using individual and multi-substrate kits under identical conditions. The two strains were grown at $22{ }^{\circ} \mathrm{C}$ in liquid or on solid $1 / 10$ strength TSB at $\mathrm{pH}$ 7.2. The individual tests included: Gram designation ( $\mathrm{KOH}$ method), staining of cells with Sudan Black to detect poly- $\beta$-hydroxybutyrate granules (examined by Nomarski interference contrast microscopy at $\times 1000$ magnification), oxidase activity (BBL Dryslide Oxidase kit), catalase activity $\left(\mathrm{H}_{2} \mathrm{O}_{2}\right.$ addition), oxidation or fermentation of glucose (Hugh \& Leifson, 1953), casein hydrolysis (detection of clearing zones on LB agar enriched with $3 \%$ skimmed milk), lysozyme activity (EnzChek Lysozyme test kit; Invitrogen), DNase activity (detection of clearing zones made visible after addition of $1 \mathrm{M} \mathrm{HCl}$ ) in

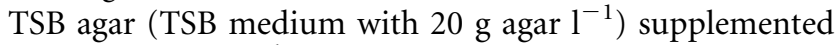
with $2 \mathrm{~g} \mathrm{DNA}^{-1}$ (Jeffries et al., 1957), and chitinase, cellulose and starch degradation using the methyl-umbelliferyl (MUF) substrate analogues MUF- $N$-acetyl- $\beta$-glucosaminide, MUF- $\beta$-glucosidase and MUF- $\alpha$-glucosidase (Sigma-Aldrich). The MUF substrates were applied as previously described (O'Brien \& Colwell, 1987). Briefly, substance from several colonies was rubbed onto $4 \mathrm{~cm}$ filter paper discs to which the MUF substrates were added. The discs were incubated at $28{ }^{\circ} \mathrm{C}$ for $30 \mathrm{~min}$ in closed Petri dishes with a drop of water to eliminate desiccation. Finally, $50 \mu \mathrm{l}$ of a saturated solution of $\mathrm{NaHCO}_{3}$ was added to each disc. The discs were examined under UV light and appearance of blue fluorescence was used to score a positive reaction. Anaerobic growth was examined by incubating the strain on pure TSB agar or TSB agar enriched with $10 \mathrm{mM}$ glucose, nitrate or sulfate, respectively, in an Oxoid AnaeroGen system.

Phenotypic characterization of strain $389^{\mathrm{T}}$ and $V$. indigofera DSM $3303^{\mathrm{T}}$ was performed by multi-substrate kits that included API $20 \mathrm{NE}$, API $50 \mathrm{CH}$ (carbohydrate utilization) and API ZYM (various enzymes) (bioMérieux), and Biolog GN2 MicroPlate and EcoPlate (Biolog). These tests were carried out according to procedures recommended by the manufacturers. For analysis of whole-cell fatty acids, cells of strain $389^{\mathrm{T}}$ and $V$. indigofera DSM $3303^{\mathrm{T}}$ were grown in TSB. Cultures for DNA-DNA hybridization were grown in TSB (strain $389^{\mathrm{T}}$ ) or R2A (Becton Dickinson) (V.perlucida LMG $24214^{\mathrm{T}}$ ). Genomic DNA G $+\mathrm{C}$ content and wholecell fatty acids were analysed by the DSMZ (Braunschweig, Germany) using HPLC analysis and GC-MS, respectively. DNA-DNA hybridization (duplicate analysis) was performed by the DSMZ according to De Ley et al. (1970).

Capacity for degradation of extracellular PG was examined by two different approaches. PG of Erythrobacter sp. (class Alphaproteobacteria) was purified by the procedure of Pelz et al. (1998). Briefly, the extraction included the following steps: treatment with SDS at $100{ }^{\circ} \mathrm{C}$ for $1 \mathrm{~h}$ for lysis of the cells, sonication for $1 \mathrm{~min}$ for additional cell destruction, proteinase treatment (trypsin) to remove proteins, and lipid extraction using organic solvents of decreasing polarity. The purified PG was added to $20 \mathrm{ml}$ samples of either $1 / 25$ strength liquid TSB or $1 / 25$ strength TSB agar applied to $1 / 25$ strength TSB agar plates as a top agar layer. A final PG concentration of $2 \mathrm{mg}^{-1}$ was used in liquid media as well as in the top agar. In the $1 / 25$ strength liquid TSB medium, growth of the inoculum was measured as the increase in cell density (determined as concentration of DNA; see below) compared to controls (1/25 strength TSB without PG). After 3, 5 and 7 days, $50 \mu$ SYBR Green 1 stain for quantification of dsDNA (product no. S7563, diluted 1:10000; Invitrogen) was added to triplicate subsamples of $2 \mathrm{ml}$. The fluorescence intensity (excitation $498 \mathrm{~nm}$; emission $520 \mathrm{~nm}$ ) was read after $10 \mathrm{~min}$ of incubation in the dark. For examination of PG degradation on solid media, cells were spread on 1/25 TSB plates with and without PG-containing top agar. Degradation (hydrolysis) of PG was determined from clearing (opaque) zones surrounding the colonies.

Growth capacity of the strains was determined at different temperatures $\left(3,5,10,20,25,30\right.$ and $\left.37^{\circ} \mathrm{C}\right)$, salinities $(0$, $1,3,6$ and $10 \%, \mathrm{w} / \mathrm{v}, \mathrm{NaCl})$ and $\mathrm{pH}(5,6,7,8,9$ and 10$)$ in $1 / 10$ or full-strength TSB medium incubated on a shaking table at $20{ }^{\circ} \mathrm{C}$ (or at $3-37^{\circ} \mathrm{C}$ for the temperature preference experiment). The growth rate of strain $389^{\mathrm{T}}$ was measured for cultures growing at $20{ }^{\circ} \mathrm{C}$ in $1 / 10$ and full-strength TSB.

Cell morphology and cell size of strain $389^{\mathrm{T}}$ were determined by scanning electron microscopy (SEM) analysis of cells from an overnight culture grown in $1 / 10$ TSB and collected on $0.2 \mu \mathrm{m}$ (pore size) polycarbonate filters. Fixation and dehydration was according to the procedure described by Watson et al. (1980). Finally the filters were mounted on aluminium stubs and sputtercoated with gold/palladium. The preparations were analysed with a Quanta 200 SEM microscope (FEI). Cell sizes were measured by using LCS Lite software (Leica Microsystems). For transmission electron microscopy (TEM) to detect presence of flagella, a drop of the overnight culture was placed on a Formvar-coated copper grid (mesh 200; Electron Microscopy Sciences). The cells were treated with $1 \%$ uranyl acetate before visualization of the negatively stained cells by using a Phillips TEM, CM 100, equipped with a Morada 11 Mbit pixel camera.

Genomic DNA was isolated from strain $389^{\mathrm{T}}$ grown overnight in TSB medium as described previously (Brandt et al., 2006). The 16S rRNA gene was amplified by PCR using the primer pair Fd1 and Rd1 (Brandt et al., 1999). The PCR product was purified by using a Qiagen PCR purification kit (cat. no. 28106, Qiagen). The almost complete $16 \mathrm{~S}$ rRNA gene sequence (1444 bp) was obtained by sequencing the gene in both directions using several forward and reverse sequencing primers (GATC Biotech). Preliminary phylogenetic analysis was carried out by using BLAST (Johnson et al., 2008) and Seqmatch (RDP 10 website; Cole et al., 2009). Based on taxonomic and sequence quality criteria, a subset of sequences was selected for subsequent alignment and final phylogenetic analysis as 


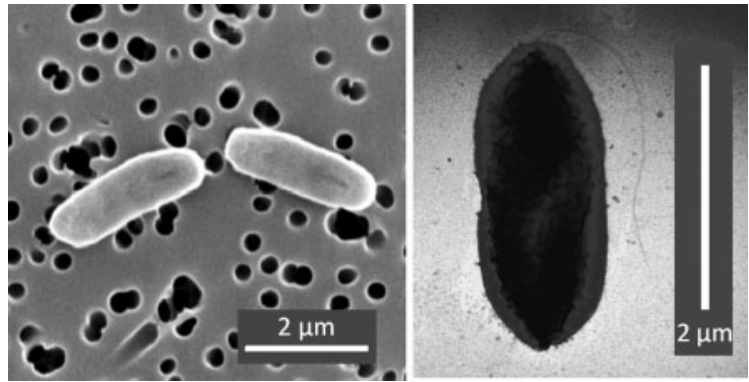

Fig. 1. Cells of strain $389^{\top}$ observed by scanning electron microscopy (SEM; left) and transmission electron microscopy (TEM; right). The polar flagellum could only be visualized by TEM.

described previously (Jørgensen et al., 2009) using BioEdit version 7.0.9.0 (Hall, 1999) and CLUSTAL X 2.0 software (Larkin et al., 2007).

Strain $389^{\mathrm{T}}$ consists of rod-shaped, motile cells (one polar flagellum was observed; Fig. 1) showing accumulation of poly- $\beta$-hydroxybutyrate granules, as previously observed for the other three species of the genus Vogesella (Chou et al., 2008, 2009; Grimes et al., 1997). The strain forms transparent colonies and lacks the characteristic blue pigmentation found in V. indigofera ATCC $19706^{\mathrm{T}}$ (Grimes et al., 1997). The fatty acid profile of strain $389^{\mathrm{T}}$ is dominated by $\mathrm{C}_{16: 1} \omega 7 \mathrm{c}$ and/or iso- $\mathrm{C}_{15: 0} 2-\mathrm{OH}$ (together also named 'summed feature 3') that account for a total of $71.6 \%$ of the fatty acids, followed by $\mathrm{C}_{16: 0}$ and $\mathrm{C}_{10: 0} 3-\mathrm{OH}$ (Table 1 ). The proportion of 'summed feature 3 ' is higher than in the other Vogesella strains and that of $\mathrm{C}_{16: 0}$ is lower, but the abundance of the remaining fatty acids equals approximately $20 \%$ as also observed in the other three Vogesella strains.

A characteristic feature of strain $389^{\mathrm{T}}$ is its capacity to degrade PG isolated from bacterial cell walls. When 1/25 strength TSB medium was enriched with PG, a 1.4- to 1.7fold higher cell density was found (liquid media) and opaque clearing zones occurred around the colonies (solid agar medium) (Fig. S1, available in IJSEM Online, and Table 2). By contrast, no utilization of PG was observed by $V$. indigofera DSM $3303^{\mathrm{T}}$ or $V$. perlucida LMG $24214^{\mathrm{T}}$. When $1 / 25$ strength TSB was replaced by mineral media, no growth on PG was observed for strain $389^{\mathrm{T}}$ (data not shown). Strain $389^{\mathrm{T}}$ was capable of degrading several other polymer compounds, including casein, gelatin, chitin, starch and Tween 80, and had DNase and lysozyme activities (Table 2). Cellulose was not degraded. Phenotypic characteristics with respect to utilization of various polymer compounds and carbon sources by strain $389^{\mathrm{T}}$ and other Vogesella strains are shown in Table 2.

Lysozyme and chitinase activities indicated that strain $389^{\mathrm{T}}$ was capable of breaking $\beta(1,4)$ glycosidic bonds in chitin and PG, and this might explain its success in utilizing cell-wall material from Gram-positive and Gram-negative bacteria as observed during the initial screening. Capacity to degrade chitin and PG has not previously been reported for members of the genus Vogesella. The opaque rather than transparent clearing zones around the colonies on PG-enriched agar may indicate only partial degradation of PG, possibly supporting the observed, positive reaction with $\mathrm{N}$-acetylglucosamine. $\mathrm{N}$-acetylglucosamine is part of the polymeric structure of both chitin and PG and is one of the most abundant monomers (amino sugars) in the biosphere (Cauchie, 2002). In contrast to the other species of the genus Vogesella, strain $389^{\mathrm{T}}$ showed only weak growth on D-glucose (Table 2 ). This suggests that the glucose moiety of PG is not a major source of nutrients for strain $389^{\mathrm{T}}$.

Phylogenetic analysis of the 16S rRNA gene sequence clearly showed that strain $389^{\mathrm{T}}$ belonged to the genus Vogesella (Fig. 2). Based on evolutionary distance and bootstrap analysis, strain $389^{\mathrm{T}}$ formed a monophyletic group with $V$. perlucida $\mathrm{DS}-28^{\mathrm{T}} \quad(99.1 \%$ nucleotide similarity), whereas it was less related to $V$. indigofera ATCC $19706^{\mathrm{T}}$ (96.9\% similarity) and V. lacus LMG $24504^{\mathrm{T}}$ (96.8\% similarity). The DNA G + C content of strain $389^{\mathrm{T}}$ was $61.2 \mathrm{~mol} \%$. Due to the close relationship with $V$.

Table 1. Dominant whole-cell fatty acid composition (\%) of strain $389^{\top}$ and related species of the genus Vogesella

Strains: 1 , strain $389^{\mathrm{T}} ; 2, V$. indigofera DSM $3303^{\mathrm{T}} ; 3$, V. perlucida DS-28 $8^{\mathrm{T}}$ (data from Chou et al., 2008); 4, V. lacus LMG $24504^{\mathrm{T}}$ (Chou et al., 2009). Fatty acids representing $<0.5 \%$ of the total are not shown.

\begin{tabular}{|lrrrr|}
\hline Fatty acid & $\mathbf{1}$ & $\mathbf{2}$ & $\mathbf{3}$ & $\mathbf{4}$ \\
\hline $\mathrm{C}_{10: 0}$ & 2.3 & 2.6 & 2.4 & $<0.5$ \\
$\mathrm{C}_{10: 0} 3-\mathrm{OH}$ & 5.5 & 5.1 & 4.8 & 4.2 \\
$\mathrm{C}_{12: 0}$ & 3.4 & 2.7 & 2.9 & 1.8 \\
$\mathrm{C}_{14: 0}$ & 2.0 & 0.6 & 1.2 & 0.9 \\
$\mathrm{C}_{16: 1} \omega 7 c$ and/or iso- $\mathrm{C}_{15: 0} 2-\mathrm{OH}^{*}$ & 71.6 & 56.9 & 61.7 & 60.0 \\
$\mathrm{C}_{16: 0}$ & 8.2 & 26.4 & 18.1 & 13.6 \\
$\mathrm{C}_{18: 1} \omega 7 c$ & 2.0 & 4.8 & 3.8 & 12.5 \\
\hline
\end{tabular}

*Also known as 'summed feature 3'. 
Table 2. Selected differential characteristics of strain $389^{\top}$ and the three recognized species of the genus Vogesella

Strains: 1, strain $389^{\mathrm{T}} ; 2$, V. indigofera ATCC $19706^{\mathrm{T}}$; 3, V. perlucida DS-28 ${ }^{\mathrm{T}}$ (data from Chou et al., 2008, except for DNA-DNA similarity); 4, V. lacus LMG $24504^{\mathrm{T}}$ (Chou et al., 2009). +, Positive reaction; (+), weakly positive reaction; -, no reaction; NA, no data available.

\begin{tabular}{|c|c|c|c|c|}
\hline Characteristic & 1 & 2 & 3 & 4 \\
\hline Isolation source & Lake water & Pond sediment & Spring water & Pond water \\
\hline Colony colour & Colourless to greyish & Blue & Colourless to white & Colourless \\
\hline DNA G $+C$ content $(\mathrm{mol} \%)$ & 62.1 & 65.4 & 61.8 & 63.0 \\
\hline $\begin{array}{l}\text { DNA-DNA similarity relative to strain } 389^{\mathrm{T}} \\
(\%)^{*}\end{array}$ & NA & NA & $50.6 \pm 9.6$ & NA \\
\hline \multicolumn{5}{|l|}{ Hydrolysis of polymers } \\
\hline Casein & + & - & - & + \\
\hline Cellulose & - & NA & - & - \\
\hline Gelatin (liquefaction) & + & - & + & - \\
\hline Chitin & + & - & - & NA \\
\hline Starch & + & - & - & - \\
\hline Tween 80 & + & - & + & + \\
\hline DNase & $(+)$ & $+\dagger$ & - & $(+)$ \\
\hline Lysozyme & + & $\mathrm{NA}$ & NA & $\mathrm{NA}$ \\
\hline \multicolumn{5}{|l|}{ Assimilation of carbon sources } \\
\hline D-Glucose & $(+)$ & + & + & + \\
\hline D-Fructose & + & - & + & + \\
\hline Glycogen & + & $\mathrm{NA}$ & + & + \\
\hline Gluconate & + & - & - & - \\
\hline Propionate & + & + & - & - \\
\hline L-Ornithine & - & + & - & + \\
\hline \multicolumn{5}{|l|}{ Degradation of PG } \\
\hline Liquid culture $\ddagger$ & + & - & NA & NA \\
\hline Agar\$ & + & - & - & NA \\
\hline
\end{tabular}

${ }^{*}$ Mean $\pm \mathrm{SD}(n=2)$.

$\dagger$ Data on DNase from Grimes et al. (1997).

¥After 3 days, cell densities of strain $389^{\mathrm{T}}$ were 1.4- to 1.7 -fold higher than densities of $V$. indigofera DSM $3303^{\mathrm{T}}$ in the PG-supplemented cultures. No differences between the two strains were found in the cultures without PG. No changes in cell densities were observed at days 5 and 7 , relative to day 3. Densities of cells were determined with the SYBR Green1 assay.

§Opaque zones of 4-8 mm were found around colonies of strain $389^{\mathrm{T}}$ on PG-enriched agar, but no similar zones were observed for $V$. indigofera DSM $3303^{\mathrm{T}}$ or V. perlucida LMG $24214^{\mathrm{T}}$ on agar supplemented with PG. Colonies on agar without PG did not produce opaque zones for any of the strains.

perlucida DS- $28^{\mathrm{T}}$, based on $16 \mathrm{~S}$ rRNA gene sequence and genomic DNA G+C content (Table 2), a DNA-DNA hybridization experiment was performed to compare strain
$389^{\mathrm{T}}$ and $V$. perlucida LMG $24214^{\mathrm{T}}$. The DNA reassociation showed $50.6 \pm 9.6 \%$ similarity between the two strains and indicated that strain $389^{\mathrm{T}}$ belongs to a novel species

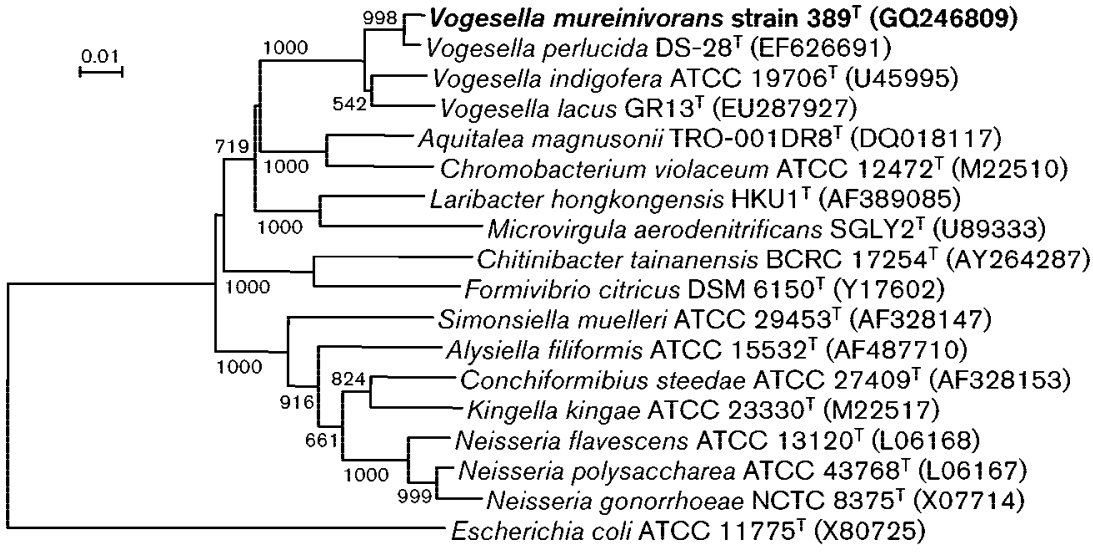

Fig. 2. Unrooted neighbour-joining phylogenetic tree based on 16S rRNA gene sequences from strain $389^{\top}$ and related type strains. Numbers at nodes indicate bootstrap values based on 1000 resampled datasets; values below 500 are not shown. Bar, $0.01 \mathrm{nt}$ substitutions per site. GenBank accession numbers are shown in parentheses. 
(Wayne et al., 1987) (Table 2). Based on the phenotypic and genotypic characters, we propose to classify strain $389^{\mathrm{T}}$, isolated from lake water, as the type strain of Vogesella mureinivorans sp. nov.

\section{Description of Vogesella mureinivorans sp. nov.}

Vogesella mureinivorans (mu.re.i.ni.vo'rans. N.L. n. mureinum murein, cell wall; L. part. adj. vorans eating, devouring; N.L. part. adj. mureinivorans murein-devouring).

Cells are Gram-negative, short rods, non-sporulating and $2.7 \pm 0.9 \times 0.8 \pm 0.1 \mu \mathrm{m}$ (mean $\pm \mathrm{SD}, n=16)$ in size. Cells are motile by means of a single polar flagellum and accumulate poly- $\beta$-hydroxybutyrate granules. Growth occurs on TSB from $5-37^{\circ} \mathrm{C}$ and $\mathrm{pH} 6-9$, with optima at $20-30{ }^{\circ} \mathrm{C}$ and pH 6-7, respectively. Doubling times in $1 / 10$ and full strength TSB at optimum conditions are 4.3 and $1.6 \mathrm{~h}$, respectively. Concentrations of up to $1 \% \mathrm{NaCl}$ are tolerated, but optimum growth occurs at $0.1 \% \mathrm{NaCl}$. After $24 \mathrm{~h}$ of growth on LB or TSB, colonies are circular with a lobate margin, low convex, smooth, nonfluorescent and transparent to slightly greyish. Hydrolyses aesculin, gelatin, glycogen, casein, PG and Tweens 40 and 80 . Positive enzyme activities include lysozyme, DNase, casein protease, $\beta$-1,4-glucanase, chitinase, chitobiase, leucine and valine arylamidases, and acid and alkaline phosphatases. The following compounds support growth: D-glucose (weak reaction), D-fructose, L-fucose, glycerol, myo-inositol, D-mannitol, methyl-pyruvate, mono-methyl succinate, acetic acid, cis-aconitic acid, formic acid, D-gluconic acid, $\alpha-, \beta$ - and $\gamma$-hydroxybutyric acids, $p$-hydroxyphenylacetic acid, itaconic acid, $\alpha$-ketobutyric acid, $\alpha$-ketoglutaric acid, $\alpha$-ketovaleric acid, DL-lactic acid, propionic acid, quinic acid, D-saccharic acid, sebacic acid, succinic acid, bromosuccinic acid, succinamic acid, L-alaninamide, D-alanine, L-alanine, L-alanyl glycine, L-asparagine, L-aspartic acid, Lglutamic acid, glycyl L-aspartic acid, glycyl L-glutamic acid, L-histidine, L-leucine, L-phenylalanine, L-proline, L-pyroglutamic acid, L-threonine, $\gamma$-aminobutyric acid, $\mathrm{N}$-acetylglucosamine and urocanic acid. Compounds that do not support growth are L- or D-arabinose, L or D-xylose, Dgalactose, L-rhamnose, L-arginine, L-ornithine, L-tryptophan and urea. Nitrate is reduced to nitrite, but the reduction is not coupled to anaerobic growth. Anaerobic growth is not observed, and oxidation and fermentation of D-glucose are negative (Hugh-Leifson test). The DNA G + C content of the type strain is $61.2 \mathrm{~mol} \%$. The predominant fatty acids are $\mathrm{C}_{16: 1} \omega 7 c$ and/or iso- $\mathrm{C}_{15: 0} 2-\mathrm{OH}$.

The type strain is $389^{\mathrm{T}}\left(=\right.$ DSM $\left.21247^{\mathrm{T}}=\mathrm{LMG} 25302^{\mathrm{T}}\right)$ isolated from the clear-water Lake Sjælsø, Zealand, Denmark.

\section{Acknowledgements}

We thank Ann Siri Berg Hentze, Susanne Iversen, Dorte Rasmussen and May Britt Prahm for competent laboratory assistance during isolation and characterization of the strain. The project was supported by The Danish Natural Science Research Council, grant no. 21010537 to N.O.G.J. and O.N.; K.K.B. acknowledges support from the Center for Environmental and Agricultural Microbiology (CREAM), funded by the Willum Kann Rasmussen Foundation.

\section{References}

Brandt, K. K., Patel, B. K. C. \& Ingvorsen, K. (1999). Desulfocella halophila gen. nov., sp. nov., a halophilic, fatty-acid-oxidizing, sulfate-reducing bacterium isolated from sediments of the Great Salt Lake. Int J Syst Bacteriol 49, 193-200.

Brandt, K. K., Petersen, A., Holm, P. E. \& Nybroe, O. (2006). Decreased abundance and diversity of culturable Pseudomonas spp. populations with increasing copper exposure in the sugar beet rhizosphere. FEMS Microbiol Ecol 56, 281-291.

Cauchie, H.-M. (2002). Chitin production by arthropods in the hydrosphere. Hydrobiologia 470, 63-95.

Chou, Y.-J., Chou, J.-H., Lin, M.-C., Arun, A. B., Young, C.-C. \& Chen, W.-M. (2008). Vogesella perlucida sp. nov., a non-pigmented bacterium isolated from spring water. Int J Syst Evol Microbiol 58, 2677-2681.

Chou, J.-H., Chou, Y.-J., Arun, A.-B., Young, C.-C., Chen, C. A., Wang, J.-T. \& Chen, W.-M. (2009). Vogesella lacus sp. nov., isolated from a soft-shell turtle culture pond. Int J Syst Evol Microbiol 59, 2629-2632.

Cole, J. R., Wang, Q., Cardenas, E., Fish, J., Chai, B., Farris, R. J., Kulam-Syed-Mohideen, A. S., McGarrell, D. M., Marsh, T. \& other authors (2009). The Ribosomal Database Project: improved alignments and new tools for rRNA analysis. Nucleic Acids Res 37, D141D145.

De Ley, J., Cattoir, H. \& Reynaert, A. (1970). The quantitative measurement of DNA hybridization from renaturation rates. Eur $J$ Biochem 12, 133-142.

Eisenstadt, E., Carlton, B. C. \& Brown, B. J. (1994). Gene mutation. In Methods for General and Molecular Bacteriology, pp. 297-316. Edited by P. Gerhardt, R. G. E. Murray, W. A. Wood \& N. R. Krieg. Washington, DC: American Society for Microbiology.

Frette, L., Johnsen, K., Jørgensen, N. O. G., Nybroe, O. \& Kroer, N. (2004). Functional characteristics of culturable bacterioplankton from marine and estuarine environments. Int Microbiol 7, 219-227.

Grimes, D. J., Woese, C. R., MacDonell, M. T. \& Colwell, R. R. (1997). Systematic study of the genus Vogesella gen. nov. and its type species, Vogesella indigofera comb. nov. Int J Syst Bacteriol 47, 19-27.

Hall, T. A. (1999). BioEdit: a user-friendly biological sequence alignment editor and analysis program for Windows 95/98/NT. Nucleic Acids Symp Ser 41, 95-98.

Hugh, R. \& Leifson, E. (1953). The taxonomic significance of fermentative versus oxidative metabolism of carbohydrates by various Gram negative bacteria. J Bacteriol 66, 24-26.

Jeffries, C. D., Holtman, D. F. \& Guse, D. G. (1957). Rapid method for determining the activity of microorganisms on nucleic acids. J Bacteriol 73, 590-591.

Johnson, M., Zaretskaya, I., Raytselis, Y., Merezhuk, Y., McGinnis, S. \& Madden, T. L. (2008). NCBI BLAST: a better web interface. Nucleic Acids Res 36, W5-W9.

Jørgensen, N. O. G., Brandt, K. K., Nybroe, O. \& Hansen, M. (2009). Delftia lacustris, sp. nov., a peptidoglycan-degrading bacterium from freshwater and emended description of D. tsuruhatensis as a peptidoglycan-degrading bacterium. Int J Syst Evol Microbiol 59, 2195-2199.

Larkin, M. A., Blackshields, G., Brown, N. P., Chenna, R., McGettigan, P. A., McWilliam, H., Valentin, F., Wallace, I. M., Wilm, A. \& other 
authors (2007). CLUSTAL $\mathrm{W}$ and CLUSTAL $\mathrm{X}$ version 2.0. Bioinformatics 23, 2947-2948.

Nagata, T., Meon, B. \& Kirchman, D. L. (2003). Microbial degradation of peptidoglycan in seawater. Limnol Oceanogr 48, 745-754.

O’Brien, M. \& Colwell, R. R. (1987). A rapid test for chitinase activity that uses 4-methylumbelliferyl- $\mathrm{N}$-acetyl-beta-D-glucosaminide. Appl Environ Microbiol 53, 1718-1720.

Pelz, O., Cifuentes, L. A., Hammer, B. T., Kelley, C. A. \& Coffin, R. B. (1998). Tracing the assimilation of organic compounds using $\delta^{13} \mathrm{C}$ analysis of unique amino acids in the bacterial peptidoglycan cell wall. FEMS Microbiol Ecol 25, 229-240.
Watson, L. P., McKee, A. E. \& Merrel, B. R. (1980). Preparation of microbiological specimens for scanning electron microscopy. Scan Electron Microsc 2, 45-56.

Wayne, L. G., Brenner, D. J., Colwell, R. R., Grimont, P. A. D., Kandler, O., Krichevsky, M. I., Moore, L. H., Moore, W. E. C., Murray, R. G. E. \& other authors (1987). International Committee on Systematic Bacteriology. Report of the ad hoc committee on reconciliation of approaches to bacterial systematics. Int $J$ Syst Bacteriol 37, 463-464.

Whitman, W. B., Coleman, D. C. \& Wiebe, W. J. (1998). Prokaryotes: The unseen majority. Proc Natl Acad Sci U S A 95, 6578-6583. 